EDWARD WORNAR

Lipšćanska uniwersita

ORCID: 0000-0001-6889-7289

e-mail: edi.werner@gmx.de

\title{
K ETYMOLOGIJI PSŁ. *SLĚPЪ/SLEPЪ
}

W staršich etymologiskich słownikach so tutón wšitkim słowjanskim rěčam zhromadny leksem zdźěla wuwostaji: Pola Vasmera (1955) pobrachuje, ani Pokorny ničo njepodawa w swojim indogermanskim słowniku (Pokorny 1959). Brückner (1957: ślepy) ma twórbu za prasłowjansku a njepodawa žane zwonkasłowjanske paralele. Machek (1957, 1968) drje spyta lit. žlibas >slepjeny< tu nawjazać, štož pak po našim měnjenju ze zwukowych přičin móžno njeje ${ }^{1}$. Tež pola Šewca (1978) tute hesło namakamy; při tym so nowši słownikarjo (kaž Gluhak 1993 a Černych 1999) na Šewca zepěraja, najskerje tež tohodla, dokelž spyta jenož Šewc za tute słowo paralele zwonka słowjanskich rěčow namakać².

Šewc staji psł. *slěpъ k lit. lipti, limpa >so lěpić‘, lipus >přiwisliwy ${ }^{3} \iota$, hs. lěpić a pod. k idg. korjenjej *lei- >slinaty८, *leip- >so lěpić« z s mobile a wujasni semantiku: »Der Blinde war für den Slawen dann urspr. der >Mensch mit tränenden (d. i. schwachen) Augen [...] « a přirunuje lit. žlibti (ke kotremuž słuša wot Macheka naspomnjene žlibas), kotrež so staji k idg. * glei-/glei >sliny $\iota^{4}$.

Etymologija so nam zda dwělomna. Sprěnja so w starych časach njerozeznawaše mjez ćělnymi a duchownymi zbrašenosćemi. Wšak je druhdy ćežko to jedne wot druheho rozeznawać, hdyž na př. njewěš, hač će něchtó njesłyši/njewidźi (ćělny brach) abo njerozumi (duchowny brach). Tež towaršnostne sćěwki su husto samsne (njesamostatnosć, trěbnosće zakońskeho zastaraćela atd.). Při tym so pak hłuposć hišće bóle z hłuchosću zwjaza hač ze sleposću, a hłuši běchu w zašłych lětstotkach wjele bóle

1 Tak hižo Skok (1971) tutu hypotezu wotpokazuje, hačrunjež Šewc (1978) Macheka sćěhuje.

2 Skok (1971) drje ma zwisk z idg. korjenjom *sel- za prawdźepodobne, widźi pak sam problematiku postulowaneje determinanty -p- kaž tež refleksow wočakowaneje metatezy likwidow a so tuž na samnsym městnje wot tuteje hypotezy zaso zdaluje. Gluhak (1993 - slijep) přirunuje łać. lippus, tu pak je zwukowy problem zdwojeneho $p$, štož Gluhak ad hoc jako ekspresiwnu geminatu interpretuje.

3 Nichtó hišće njeje namjetował, semantiski zwisk z přiwisliwosću tak interpretować, zo dyrbi so čłowjek, kiž njewidźi abo jara hubjenje widźi, wodźić.

${ }^{4}$ Zwisk z lit. žlibti ma Snoj (1997 - slêp) za najbóle prawdźepodobne wujasnjenje a wuchadźa z idg. *^kleibo- >šělhawy<, štož so pak zwukowje k žanemu z leksemow tak prawje njehodźi. 
wot towaršnosće wuzamknjeni hač slepi ${ }^{5}$. Tak słušatej ně. taub >hłuchi a doof >hłupikojty< hromadźe, jendź. dumb >hłuchi, němy, hłupy< k ně. dumm ${ }^{6}$, psł. *gluchъ >hłuchiく k lit. glušas ’hłupak, (tež: hłuchi čłowjek)<. Idg. *bud(e)ros ’hłuchiく so kontinuuje w kymr. byddar >hłuchiく, korjeń pak woznamjenja prěnjotnje - kaž jendźelsce dumb tež >němy< a >hłupy< (př. Pokorny 1959 - bud( ()ros); ně. blind słuša k blenden, prěnjotnje >měšećく (přir. jendźelsce to blend) a psł. *błǫdъ a z tym tež k hs. błudny, błudźić a kymr. dall >slepy< stuša ke got. dwals >hłupy<, lit. dūlinti >błudźićく. Tuž bychmy zwoprědka wočakowali, zo pokazuje psł. *slěpъ na někajki ćělny $a$ duchowny brach.

Zdruha je Šewcowa paralela lit. žlibas njewěsta, dokelž so lit. aklas a žlibas semantisce rozeznawatej (hačrunjež słowniki husto jenož >slepy< podawaja). Z aklas (kiž kontinuuje idg. słowo za slepy a słaby) so po informaciji maćeršćinarjow asociěruje stajny brach, mjeztym zo je žlibas skerje přechodny staw, wosebje zawinjeny přez jaskrawe swětło, tak zo woči sylzujetej. Podzynk hłuposće abo njerozumnosće ma jenož aklas, nic pak žlibas, na př. aklas/**žlibas pyktis, akla/**žliba laimé >slepy hněw, slepe zbožoく. Nimo toho sej žlibas zwukowje * ĝlei- jako wuchadźišćo žada, dalše wot Šewca to přirjadowane słowa kaž gleimès >sliž` pak *glei-, tak zo njemóžemy ani z wěstosće prajić, zo so jedna wo samsny korjeń. Kentumowe zastupowanja drje su w baltiskich rěčach znate (přir. lit. karvẻ 〉kruwaく vs. apr. sirwis >jeleńく, kiž so wobě na *^ker-uno- wróćo wjedźetej). Ale njewěsta etymologija zda so hišće bóle dwělomna, hdyž so na tajke njeprawidłownosće zepěra.

Střeća dźě zda so interpretacija sleposće jako sylzojtej woči semantisce hišće akceptabelna, ale Šewcowa interpretacija pomina so dodatnu kročel lěpjaty $\rightarrow$ slinaty $\rightarrow$ sylzojty $\rightarrow$ slepy. Dalša móžnosć by snano była metafra lěpjatych $\rightarrow$ zalěpjenych woči, ale to so nam zda wjele mjenje plawsibelne.

A na kóncu njemóže Šewcowa etymologija chabłanje e/ě w korjenju wujasnić a wón praji lapidarnje: »os. slepy hat kurzen Wurzelvokalismus unklaren Ursprungs« (ibid.), hačrunjež so *e tež w pól. ślepy, poł. slepě, č. słk. slepý, błh. cлen namaka. Tuž njemóže žana etymologija spokojeć, kiž njeposkića za tute chabłanje we wokalizmje žane wujasnjenje.

Zjimajo hodźi so tuž rjec, zo je wot Šewca podata etymologija w kóždym nastupanju njespokojaca, dokelž njewujasni zwukowe wosebitosće refleksow w słowjanskich rěčach, pomina sej wosebite zwukowe a semantiske wuwića, za kotrež Šewc žane paralele abo wuchadźišća za analogije njeskići. Namjetujemy tu hinašu interpretaciju.

Wuchadźamy-li z toho, zo je leksem stary, bychmy wočakowali, zo so idg. prawidła słowotwórby w psł. rekonstrukcijach wotbłyšćuja, štož rěka: e-stopjeń w primarnym adjektiwje (*slepъ), nulowy stopjeń we werbje přechoda (*sblpnǫti) ${ }^{7}$, o-stopjeń abo podlěšeny stopjeń w kawsatiwje/iteratiwje (*slopiti/*slěpiti) ${ }^{8}$.

${ }^{5}$ Přir. k tutej problematice Sacks 1989.

${ }^{6}$ Přir. Kluge (2002 - dumm a taub).

${ }^{7}$ Přir. tež wot Skoka $(1971$ - slijep $)$ naspomnjenej osupnuti, słw. osupnoti. Tutón typ wotpowěduje idg. typej, reflektowanemu w sti. 5. klasy (Szemerényi 1989, 290).

${ }^{8}$ Přir. k tutym twórbam Werner (1996: 48 sć., 87 sćć.) z dalšej literaturu. Wočakowali bychmy jako primarny kawsatiw *slopiti a jako iteratiw *slěpiti, ale kawsatiwy a iteratiwy so hižo zahe měšeja (přir. Fortson 2010: 99). 
Po tutym principje móžemy chabłanje mjez $e$ a $e \check{~ j a k o ~ w u r u n a n j e ~ m j e z ~ k a w s a t i-~}$ wom a primarnym adjektiwom wujasnić, štož pak w samsnym času Šewcowe wujasnjenje wuzamkuje, dokelž sej naše wujasnjenje pomina $*_{\mathrm{e}_{111}}$ a nic $*_{\mathrm{e}_{112}}$, kiž je za Šewcowu etymologiju trěbne.

Hladamy-li do litawšćiny, bychmy tam jako słowotwórbne ekwiwalenty wočakowali *slepyti/slapýti (za kawsatiw), silpnéti (za werb přechoda) a ? slepas jako primarny adjektiw. Forma? slepas njeje dokładźena, ale slepokas (www.lkz.lt) >zamućeny, njewobhladniwy, z hubjenym widźenjomı, štož eksistencu adjektiwa *slepas předpokładuje, podobnje kaž geras - gerokas, didis - didokas, atd. ${ }^{9}$. Slapyti rěka >chować<, potajkim ze semantiskej změnu >něšto njewidźomne sčinićく. Lit. silpnèti >wosłabićく ma (prěnjotny) powšitkowny woznam słabosće, kotryž so tež w sufigowanym adjektiwje silpnas >słaby< hišće namaka. Fakt, zo so wšitke wočakowane formy znajmjeńša w jednej wotwodźenej formje namakaja, wobkrući našu słowotwórbnu hypotezu. Zwisk mjez >słaby< a >(so) chowaćく je tež wuwidźeć mjez lit. slèpti >chowaćく a slèpsna >ćeńke městnoく, prrir. Fraenkel (1965 - slëpsna).

Tuž namjetujemy, psł. *slep/*slěp/*sblp- k lit. silpnas, slapyti stajić. Tež slèpti >chowaćく a druhe móhli sem słušeć. Tutón namjet ma slědowace lěpšiny:

1. Dotal njewujasnjene chabłanje mjez *e a *ě so jako wurunanje mjez korjenjom kawsatiwa a korjenjom adjektiwa wujasni. Tute wurunanje je přez to motiwěrowane, zo njewustupuje za słowjanski čas hižo kruty systemowy rozdźěl mjez adjektiwiskim a kawsatiwowym zdónkom (přir. hs. lěpši - polěpšić, žotty - žotćić atd.). W někotrych słowjanskich rěčach je so $e$ spowšitkowniło, w druhich $\check{e}$.

2. Korjeń wustupuje baltosłowjansce we wšěch słowotwórbnje wočakowanych formach a wokolinach: *slep- w lit. slepokas, sł. slep-, *s(i)lp- w lit. silpnas >słaby<, slipneti >słaby bywaćく, stcsł. oslbpnoti >woslepićく, *slop- w lit. slapus >tajawy<, slapyti >chowaćく, slopinti >podusyćく a *slēp- w stcsł. slěpiti >slepićく (w serbšćinje z wurunanjom po adjektiwje).

3. Prěnjotna semantika >słaby< ze semantiskim zwuženjom >słaby na wočiく so za ćělne brachi wjele lěpje hodźi hač >lěpjaty`, štož Šewc interpretuje jako metafru za sylzate (= słabe) woči (hl. citat horjeka).

\section{Bibliografija}

Brückner A., 1957, Stownik etymologiczny języka polskiego, Warszawa.

Černych P.Ja., 1994, Istoriko-ètimologičeskij slovar' sovremennogo russkogo jazyka. Russkij jazyk, Moskva, 2. nakł. 1999.

Fortson B.W., 2010, Indo-European Language and Culture, Wiley-Blackwell.

Fraenkel E., 1955, Litauisches etymologisches Wörterbuch, Heidelberg.

Fraenkel E., 1965, Litauisches etymologisches Wörterbuch, Göttingen.

Gluhak A., 1993, Hrvatski etimološki rječnik, Zagreb.

Kluge F., 2002, Etymologisches Wörterbuch der deutschen Sprache, Berlin-New York.

Machek V., 1957, Etymologický slownik jazyka českého a slovenského, Praha.

Machek V., 1968, Etymologický slownik jazyka českého, Praha.

9 Snano je so *slepas za rusizm přepóznało a zaměrnje wutupiło. 
Pokorný J., 1959, Indogermanisches etymologisches Wörterbuch, München/Bern.

Sacks O., 1989, Seeing Voices: A Journey Into the World of the Deaf, Los Angeles.

Skok P., 1971, Etimologijski rječnik hrvatskoga ili srpskoga jezika, Zagreb.

Snoj M., 1997, Slovenski etimološki slovar, Ljubljana.

Schuster-Šewc H., 1978-1989, Historisch-etymologisches Wörterbuch der ober- und niedersorbischen Sprache, Bautzen.

Szemerényi O., 1980, Einführung in die historische Sprachwissenschaft, Heidelberg, 3. Aufl. 1989.

Vasmer M., 1953, Russisches Etymologisches Wörterbuch, Heidelberg.

Werner E., 1996, Studien zum sorbischen Verbum [Schriften des sorbischen Instituts 13], Budyšin.

EDWARD WORNAR

\title{
On the etymology of PSI *slep-/slěp-
}

\begin{abstract}
This article explains the hitherto unexplained variation of the root *slep/slép- 'blind' which results from an old opposition of the causative (lengthened grade) vs. regular root (regular grade). This indicates a connection with the Lithuanian silpnas as a zero-grade root for the Slavic word which previously had no convincing parallels in other languages. Semantically, a connection with words meaning 'sticky' (as postulated by Šewc 1978 and others) should be rejected: they are neither phonetically nor semantically convincing. The preference is for the interpretation of blindness as a special kind of weakness.
\end{abstract}

Keywords: etymology, Sorbian. 